Check for updates

Cite this: RSC Adv., 2018, 8, 19979

\title{
Gold decoration of silica by decomposition of aqueous gold(III) hydroxide at low temperatures $\uparrow$
}

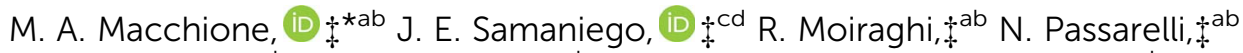

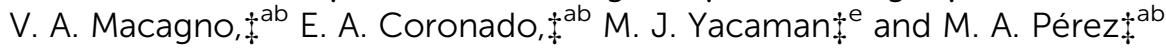

The decomposition of gold hydroxide to give metallic gold is known to take place around $300{ }^{\circ} \mathrm{C}$ in dry environments. However, little information about the gold hydroxide stability in wet environments has been recorded. Here, we present experimental evidence which shows that aqueous/water-enriched gold(III) hydroxide colloids decompose spontaneously to form gold nanoparticles at temperature values above the freezing point of water. Based on this reaction, we developed a method to decorate silica spheres with gold nanoparticles by precipitation and decomposition of gold(III) hydroxide onto the silica surface in wet media by a simple one-pot/one-step protocol. The silicalgold nanostructures are prepared in high yield and with a low level of by-products.

Received 1st February 2018

Accepted 12th May 2018

DOI: $10.1039 / \mathrm{c} 8 \mathrm{ra01032c}$

rsc.li/rsc-advances metallic gold and oxide surfaces. ${ }^{23,24}$ Among the most used synthetic approaches are the impregnation methods, which achieve the synthesis of OMP|AuNPs by triggering the formation of metallic gold from soluble gold precursors by means of chemical reduction or photochemical decomposition. ${ }^{25-28}$ Because of the poor interaction between metallic gold and oxide surfaces, ${ }^{29-32}$ gold heterogeneous nucleation from soluble species is disadvantaged versus gold homogeneous nucleation. Consequently, these methods usually lead to profuse formation of free-standing AuNPs, low gold loading on the OMPs surface and AuNPs unevenly dispersed on the substrate. This last feature makes necessary further post-synthesis purification steps to separate OMP|AuNPs from the free-standing AuNPs. All this issues can be sorted by functionalizing the OMPs in order to bind AuNPs by using molecular bridges; ${ }^{29-34}$ however, this strategy requires multiple steps and leads to variable yields. ${ }^{35}$ Another synthesis approach frequently used in catalysis is the co-precipitation/calcination method developed by Haruta and co-workers. In this synthesis, the gold(III) hydroxide $\left(\mathrm{Au}(\mathrm{OH})_{3}\right)$ is co-precipitated with different oxides and then, the composite is calcinated above $300{ }^{\circ} \mathrm{C}$ to decompose the $\mathrm{Au}(\mathrm{OH})_{3}$ and produce supported AuNPs. ${ }^{36-39}$ Despite the extremely simple procedures required, a frequent drawback of using a calcination step is the encapsulation of AuNPs with the oxide supporting material leading to the decrease of the catalytic activity. ${ }^{40,41}$ Moreover, calcination step may induce changes in the morphology of AuNPs. ${ }^{42,43}$

The dilemma of the poor wetting on oxides is common to all metals. For the case of silver, we have recently reported a onestep/one-pot method to decorate OMPs with silver nanoparticles (AgNPs). ${ }^{44}$ In our approach, we manage to overcome the wetting problem by performing, first, the silver oxide $\left(\mathrm{Ag}_{2} \mathrm{O}\right)$ precipitation onto the OMPs in aqueous media and then, as the 
aqueous $\mathrm{Ag}_{2} \mathrm{O}$ decompose at room temperature to form AgNPs, we achieved the formation of AgNPs directly attached to OMP surface. ${ }^{45,46}$ As a result, OMP $\mid$ AgNPs can be produced in a single synthesis step at room temperature, without drying the solution. Given that $\mathrm{Ag}_{2} \mathrm{O}$ has a good interaction with other oxides, its heterogeneous nucleation is more feasible than the heterogeneous nucleation of metallic silver. Thereby, the instability of aqueous $\mathrm{Ag}_{2} \mathrm{O}$ colloids at room temperature is the key factor of our synthetic approach. For the case of gold few information about the instability of aqueous $\mathrm{Au}(\mathrm{OH})_{3}$ colloids is available in literature. Besides, it is worth noting that all reports of the decoration of oxide particles using $\mathrm{Au}(\mathrm{OH})_{3}$ as precursor employ calcination to form metallic gold. In this context, the development of a synthetic method to obtain OMP|AuNPs with high yields simplifying the limiting factors of the pre-existing methods and avoiding calcination will have a great impact in areas as catalysis where the traditional methods are still used.

Here, we report experimental evidence which shows that aqueous/water-enriched media colloids of $\mathrm{Au}(\mathrm{OH})_{3}$ are unstable at temperatures above the water freezing point. Based on this behavior, we have developed a method to achieve the decoration of silica microparticles ( $\mathrm{SiO}_{2} \mathrm{MPs}$ ) with AuNPs. In order to obtain the optimal conditions for the synthesis of high quality OMP|AuNPs, we have explored the effect of experimental conditions (temperature, media polarity and species concentrations) on the instability of $\mathrm{Au}(\mathrm{OH})_{3}$ and production of AuNPs. We will refer to this synthetic approach as the Oxide Precipitation-Decomposition (OPD) method.

\section{Experimental section}

\section{Materials}

All materials were used without further purification; chloroauric acid $\left(\mathrm{HAuCl}_{4} \cdot 3 \mathrm{H}_{2} \mathrm{O}, 99.995 \%\right.$, Sigma-Aldrich), sodium hydroxide ( $\mathrm{NaOH}, 98.15 \%$, J. T. Baker), ammonium hydroxide $\left(\mathrm{NH}_{4} \mathrm{OH}, 28-30 \%\right.$, Cicarelli), ethanol (99.5\%, Cicarelli), tetraethyl orthosilicate (TEOS, 98\%, Sigma-Aldrich) and acetone (99.5, Sintorgan). Deionized purified water (Milli Q system) was used to prepare solutions (resistivity of $18.2 \mathrm{M} \Omega \mathrm{cm}$ ). $\mathrm{HAuCl}_{4}$ stock solutions were kept in darkness to prevent any photochemical reaction.

\section{General protocol to obtain the reactive mixtures}

Alkaline solutions of Au(III) which undergo the chemical change that produces AuNPs are referred herein as "reactive mixtures". To achieve the $\mathrm{Au}(\mathrm{OH})_{3}$ precipitation, a strong alkali like $\mathrm{NaOH}$ is added into solutions of $\mathrm{HAuCl}_{4}$ (gold precursor) in aqueous media or in mix solvents acetone: water. All the reactive mixtures were incubated in darkness at room temperature $(19<$ $T<24{ }^{\circ} \mathrm{C}$ ). The detailed conditions of each experiment as composition of the solutions are indicated in each figure. The $\mathrm{pH}$ values were obtained after homogenization by using $\mathrm{pH}$ indicator tape.

\section{Synthesis of $\mathrm{SiO}_{2} \mathrm{MPs}$}

Spherical silica substrate microparticles ( $\left.\mathrm{SiO}_{2} \mathrm{MPs}\right)$ were synthesized via the Stöber method ${ }^{4-49}$ using TEOS $(0.36 \mathrm{M})$ and deionized purified water $(24.08 \mathrm{M})$ as precursors in ethanolic medium (final volume of $10 \mathrm{~mL}$ ), and $\mathrm{NH}_{4} \mathrm{OH}(0.414 \mathrm{M})$ as catalyst, during 12 hours of reaction at room temperature under vigorous stirring. The resulting suspension were processed by centrifugation and separation of $\mathrm{SiO}_{2} \mathrm{MPs}$, which were finally resuspended in $40 \mathrm{~mL}$ deionized purified water to give the stock suspension used in the experiments.

The $\mathrm{SiO}_{2}$ MPs concentration can be calculated assuming that the colloid is formed by spheres of same sizes, by using the following equation:

$$
\left[\mathrm{SiO}_{2} \mathrm{MPs}\right]=\frac{6[\mathrm{TEOS}] \mathrm{PM}_{\mathrm{SiO}_{2}}}{\pi d^{3} \delta_{\mathrm{SiO}_{2} \mathrm{MPs}}}
$$

where $d$ is the $\mathrm{SiO}_{2}$ MPs average diameter, $\mathrm{PM}_{\mathrm{SiO}_{2}}$ is the silica molar weigth and $\delta_{\mathrm{SiO}_{2} \mathrm{MPs}}$ is the $\mathrm{SiO}_{2} \mathrm{MPs}$ density $\left(2.0 \mathrm{~g} \mathrm{~cm}^{-3}{ }^{50}\right)$. The $\mathrm{SiO}_{2} \mathrm{MPs}$ concentration in the alcoholic suspension $(10 \mathrm{~mL})$ is estimated to be $1.77 \times 10^{15}$ particles per liter $\left(\mathrm{SiO}_{2} \mathrm{MPs}\right.$ per $\left.\mathrm{L}\right)$. This gives an estimated concentration of $4.43 \times 10^{14} \mathrm{SiO}_{2} \mathrm{MPs}$ per $\mathrm{L}$ for the stock suspension after centrifugation and resuspension in $40 \mathrm{~mL}$. Finally, we use $0.2 \mathrm{~mL}$ of this stock suspension for each experiment (final volume of $20 \mathrm{~mL}$ ) giving $4.43 \times 10^{12} \mathrm{SiO}_{2} \mathrm{MPs}$ per L. See $\mathrm{SiO}_{2} \mathrm{MPs}$ characterization in Section ESI- $2 . \dagger$

\section{The OPD method}

In order to achieve the precipitation of $\mathrm{Au}(\mathrm{OH})_{3}$ onto the $\mathrm{SiO}_{2}$ MPs surface the reactive mixtures are prepared as follow: the alkali $(\mathrm{NaOH})$ is added to a suspension of $\mathrm{SiO}_{2} \mathrm{MPs}$ and $\mathrm{HAuCl}_{4}$ in aqueous media or in mix solvents acetone : water. Then, the reactive suspensions are incubated in darkness usually at room temperature $\left(19<T<24{ }^{\circ} \mathrm{C}\right)$.

\section{Synthesis of $\mathrm{SiO}_{2} \mathrm{MP} \mid$ AuNPs (low-T protocol)}

The $\mathrm{SiO}_{2} \mathrm{MP} \mid$ AuNPs were obtained by preparing a reactive suspension of $\mathrm{HAuCl}_{4} 0.1 \mathrm{mM}, 4.43 \times 10^{12} \mathrm{SiO}_{2} \mathrm{MPs}$ per $\mathrm{L}$ ( $0.2 \mathrm{~mL}$ of the stock suspension) and $\mathrm{NaOH} 1 \mathrm{mM}$ in a $90: 10$ acetone : water environment (final volume: $20 \mathrm{~mL}$ ). The final concentration of $\mathrm{NaOH}$ is obtained gradually in three steps. By adding an aliquot from the strong base stock solution $(\mathrm{NaOH}$ $0.1 \mathrm{M}$ ) after a time lapse of 2 hours to establish the concentration in $0.1,0.5$ and $1 \mathrm{mM}$ (final $\mathrm{pH}=8.5$ ). The beginning of the reaction time is set with the first addition of $\mathrm{NaOH}$ solution aliquot. This reactive suspension was kept in darkness under constant stirring during 8.5 hours of incubation in an ice bath.

\section{Instrumentation and measurements}

- UV-Visible: spectra were recorded with a Shimadzu UV-1200 spectrometer by using a $1 \mathrm{~cm}$ quartz cell at room temperature to periodically analyze the optical behavior along the reaction time.

- Transmission Electron Microscopy (TEM): TEM imaging was performed using JEM-JEOL 1120 and JEOL 1230 
microscopes operating at $80 \mathrm{kV}$. Samples were prepared on a Formvar covered cooper grid, without any purification treatment and evaporating it in air at room temperature.

- High Resolution Transmission Electron Microscopy (HRTEM): selected experimental samples were characterized using JEOL $2010 \mathrm{~F}$ operating at $200 \mathrm{kV}$, preparing samples on carbon covered cooper grids. Seeded grids were washed first with ethanol and then with a solution methanol : chloroform $50: 50$.

- Scanning Transmission Electron Microscopy (STEM): STEM imaging was performed using a Hitachi STEM-5500 operating at $30 \mathrm{kV}$. Samples were prepared on a Formvar covered cooper grid; seeded grids were washed only with ethanol.

- Atomic Resolution Scanning Transmission Electron Microscopy (ARM-STEM): a JEM-200ARMF JEOL microscope equipped with a CEOS Cs corrector on the illumination system operating at $200 \mathrm{kV}$ was used; samples were seed on carbon covered cooper grids. Seeded grids were washed first with ethanol and then with a solution methanol : chloroform $50: 50$.

- Energy-dispersive X-ray Spectroscopy (EDS): The elemental distribution on the NSs was studied by EDS line scanning and mapping using a JEM-200ARMF JEOL microscope. The X-ray emission signals corresponding to the $\mathrm{K}$ lines of oxygen and silicon, and the $\mathrm{L}$ line of gold were used to this purpose.

- Image processing: FFT analysis was performed using the Digital Micrograph software.

- Size distribution: the size of supported AuNPs was determined from TEM images by using Image J software. For the case of spheroidal shaped particles, the criterion assumed was to regard the major dimension determined as representative value for diameter. Average values were obtained from populations ranging from 200 to 500 particles, depending on the amount of images available for each sample. Size values higher than $20 \mathrm{~nm}$ were considered agglomerates and they were not included in the distributions.

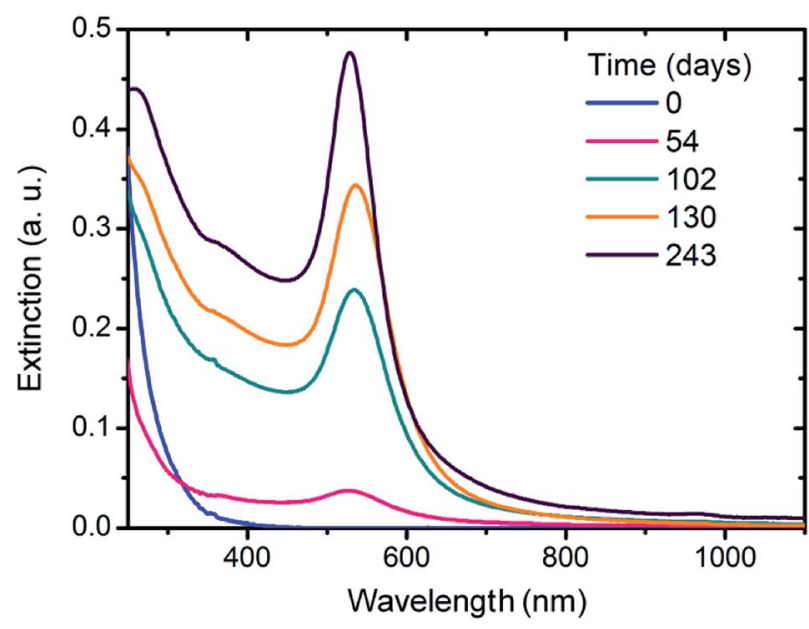

Fig. 1 Spectral evolution of a $\mathrm{HAuCl}_{4} 0.1 \mathrm{mM}$ and $\mathrm{NaOH} 5 \mathrm{mM}(\mathrm{pH}=$ 11-11.5) solution at room temperature.

\section{Results and discussion}

\section{Instability of alkaline Au(III) solutions}

Alkaline solutions of $\mathrm{Au}(\mathrm{III})$ display the spectral evolution shown in Fig. 1. Freshly prepared solutions (blue line) exhibit a decreasing extinction profile with very small extinction values between 400 and $1100 \mathrm{~nm}$. The absence of peaks associated with $\left[\mathrm{AuCl}_{4}\right]^{-}$or mixed complexes $\left[\mathrm{Au}(\mathrm{Cl})_{4-x}(\mathrm{OH})_{x}\right]^{-}$in the region between 200 and $400 \mathrm{~nm}$ confirms the complete replacement of $\mathrm{Cl}^{-}$for $\mathrm{OH}^{-}$ions either to form $\left[\mathrm{Au}(\mathrm{OH})_{4}\right]^{-}$or $\mathrm{Au}(\mathrm{OH})_{3}$ (see Section ESI-1 $\dagger$ ). In these conditions, no visible evidence of the $\mathrm{Au}(\mathrm{OH})_{3}$ precipitation was observed. After 54 days of incubation, the spectrum shows a peak located at $526 \mathrm{~nm}$ which corresponds to the surface plasmon resonance (SPR) characteristic of the presence of AuNPs. As time elapses, the intensity of the SPR peak increases whereas only a slight shift of its position can be detected (102 days: $534.5 \mathrm{~nm} ; 130$ days: $536.0 \mathrm{~nm}$ and 243 days: $528.5 \mathrm{~nm}$ ), both features consistent with the progressive formation of AuNPs. AuNPs are also formed in mixed mediums of water and acetone. Fig. 2 shows spectrum profiles for alkaline solutions of $\mathrm{Au}(\mathrm{III})$ prepared in acetone : water $50: 50$ (pink line) and in aqueous media (blue line) that were incubated at room temperature. The intensity of the extinction peak obtained after 15 minutes for the acetone : water environment is about 26 times higher than the one obtained after 6 days in the aqueous medium. The higher extinction value indicates that the formation of AuNPs from alkaline Au(III) species is notably accelerated in acetone : water environments. This has a close resemblance with results obtained for silver where the silver nanoparticles formation from aqueous $\mathrm{Ag}_{2} \mathrm{O}$ decomposition is also accelerated by employing acetone : water environments. ${ }^{45}$

The AuNPs formation from $\mathrm{Au}(\mathrm{III})$ alkaline solutions could be associated either with the redox reaction between $\left[\mathrm{Au}(\mathrm{OH})_{4}\right]^{-}$and water or with the decomposition of aqueous $\mathrm{Au}(\mathrm{OH})_{3}$ colloids. $\mathrm{Au}(\mathrm{OH})_{3}$ has been reported to undergo thermal decomposition to

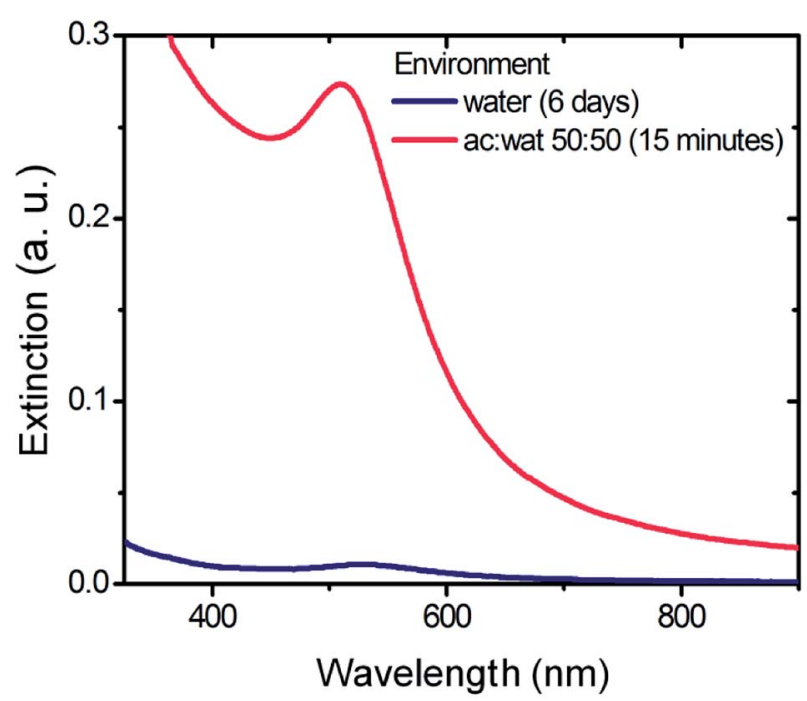

Fig. 2 UV-Visible spectra of AuNPs produced from solutions of $\mathrm{HAuCl}_{4} 0.1 \mathrm{mM}$ and $\mathrm{NaOH} 5 \mathrm{mM}$ in aqueous and $50: 50$ acetone : water media. 
produce metallic gold when calcination above $300{ }^{\circ} \mathrm{C}$ is driven in dry gaseous environments, ${ }^{51}$ in accordance to:

$$
4 \mathrm{Au}(\mathrm{OH})_{3(\mathrm{~s})} \rightarrow 4 \mathrm{Au}_{(\mathrm{s})}+3 \mathrm{O}_{2(\mathrm{~g})}+6 \mathrm{H}_{2} \mathrm{O}_{(\mathrm{l})}
$$

In aqueous media, thermodynamic calculations indicate that $\mathrm{Au}(\mathrm{OH})_{3}$ decomposes by the redox reaction in water. ${ }^{52,53}$ Nevertheless, there are only few experimental reports of the formation of metal gold from alkaline $\mathrm{Au}(\mathrm{III})$ solutions. ${ }^{54}$ According to this, in our experiment, either the $\mathrm{Au}(\mathrm{OH})_{3}$ or $\left[\mathrm{Au}(\mathrm{OH})_{4}\right]^{-}$or both can be the species that lead to the AuNPs formation. In order to obtain information about the identity of the unstable species, we explored the dependence of the Au(III) stability with the base concentration (Fig. 3). The reaction spectral profiles for alkaline $\mathrm{Au}(\mathrm{III})$ solutions prepared in aqueous media and acetone : water (50:50) with similar strong base are shown in Fig. $3 \mathrm{a}$ and b, respectively. In aqueous media (Fig. 3a), the characteristic SPR peak of the AuNPs undergoes a very noticeable decrease of its extinction value as the $\mathrm{NaOH}$ concentration is raised. Also, the SPR peak wavelength shifts gradually to larger values with the increase of base concentration: $536 \mathrm{~nm}(5 \mathrm{mM}), 543 \mathrm{~nm}(10 \mathrm{mM})$, and $553 \mathrm{~nm}(20 \mathrm{mM})$. Both features indicate that the nucleation of AuNPs is quenched by the increase of the $\mathrm{NaOH}$ concentration and, consequently, the AuNPs formed are larger in size and less in number. After the $\mathrm{Au}(\mathrm{OH})_{3}$ precipitation and due to the $\mathrm{Au}(\mathrm{III})$ amphoteric behavior, as the $\mathrm{pH}$ rises $\mathrm{Au}(\mathrm{OH})_{3}$ is dissolved to form $\left[\mathrm{Au}(\mathrm{OH})_{4}\right]^{-}(\mathrm{ESI}-1 \dagger)$. Thus, if the instable behavior of alkaline $\mathrm{Au}(\mathrm{III})$ solutions were due to the redox reaction between $\left[\mathrm{Au}(\mathrm{OH})_{4}\right]^{-}$and water, then the increase of $\mathrm{pH}$ should favor the AuNPs formation. Such a prediction is in plain contradiction with the experimental evidence shown in Fig. 3a and therefore, the hypothesis that AuNPs are the result of $\left[\mathrm{Au}(\mathrm{OH})_{4}\right]^{-}$reduction reaction is clearly inconsistent. On the other hand, the hypothesis that AuNPs are formed by the decomposition of aqueous $\mathrm{Au}(\mathrm{OH})_{3}$ colloids seems to be more effective at explaining the experimental results. The evidence indicates that the AuNPs formation is more efficient at mild alkaline $\mathrm{pH}$ at which the $\mathrm{Au}(\mathrm{OH})_{3}$ is present as a colloid. Furthermore, as the $\mathrm{pH}$ increases the formation of the AuNPs is quenched, an effect that is consistently explained by the $\mathrm{Au}(\mathrm{OH})_{3}$ re-dissolution at high $\mathrm{pH}$ values.

A similar effect on the stability of alkaline Au(III) species with the variation of $\mathrm{pH}$ is found for solutions prepared with acetone: water $50: 50$, results shown in Fig. $3 \mathrm{~b}$. The SPR peak decreases in intensity and is red-shifted as the $\mathrm{NaOH}$ concentration increases for the same reaction time. In particular, for $\mathrm{NaOH} 50 \mathrm{mM}$, the suspension exhibits a spectral profile (orange line) with small extinction values approximately constant between 400 and $800 \mathrm{~nm}$, feature consistent with the dispersion of large particles. Again, the evidence shows that AuNPs nucleation is quenched by the rise in the $\mathrm{pH}$, fact that is consistent with the $\mathrm{Au}(\mathrm{OH})_{3}$ re-dissolution to form $\left[\mathrm{Au}(\mathrm{OH})_{4}\right]^{-}$. Interestingly, the formation of AuNPs is much faster in acetone : water $50: 50$ than it is in water as has been concluded from the analysis of Fig. 2. This feature can be consistently explained by considering the AuNPs production from $\mathrm{Au}(\mathrm{OH})_{3}$ decomposition since the polarity of the media of acetone : water environments is lower than water and, as a consequence, solvated ionic species are thermodynamically disfavor versus neutral $\mathrm{Au}(\mathrm{OH})_{3}$ favoring the $\mathrm{Au}(\mathrm{OH})_{3}$ precipitation.

The experimental evidence shown in this section demonstrate that aqueous $\mathrm{Au}(\mathrm{OH})_{3}$ colloids decompose at room temperature producing AuNPs. This reaction as a fact has direct application in synthesis. Indeed, the decomposition of aqueous $\mathrm{Au}(\mathrm{OH})_{3}$ colloids represents a safety, easy and clean method to produce free-standing AuNPs with the advantage of avoiding the use of light and high temperatures to trigger the decomposition without adding any reducing agents. As we will show in next sections, this reaction also finds application in the synthesis of hybrid NSs ( $\mathrm{SiO}_{2} \mathrm{MPs} \mid$ AuNPs).

\section{Oxide Precipitation-Decomposition (OPD) method}

The evidence analyzed in the previous section show that the $\mathrm{Au}(\mathrm{OH})_{3}$ is unstable in wet environments. Based on these results, we have developed an OPD method for the synthesis of AuNPs onto the surface of OMPs. The strategy is based on overcoming the poor wetting of metallic $\mathrm{Au}$ on oxides by achieving first the precipitation of $\mathrm{Au}(\mathrm{OH})_{3}$ :
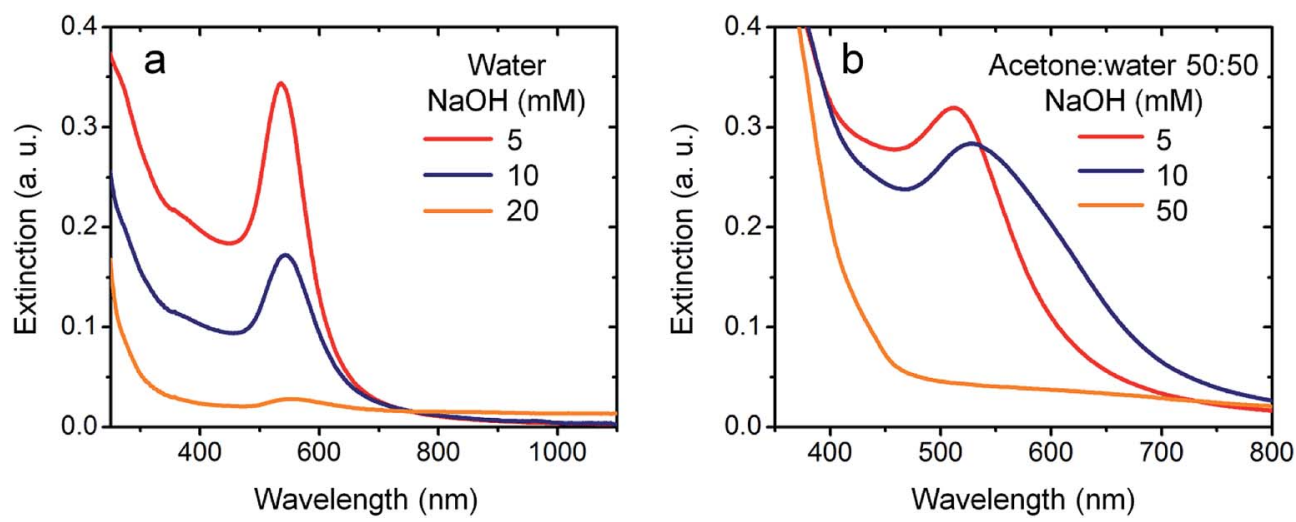

Fig. 3 UV-Visible spectra of $\mathrm{HAuCl}_{4} 0.1 \mathrm{mM}$ and different $\mathrm{NaOH}$ concentrations: (a) in water at 130 days. (b) in acetone : water 50 : 50 at 2 days. 

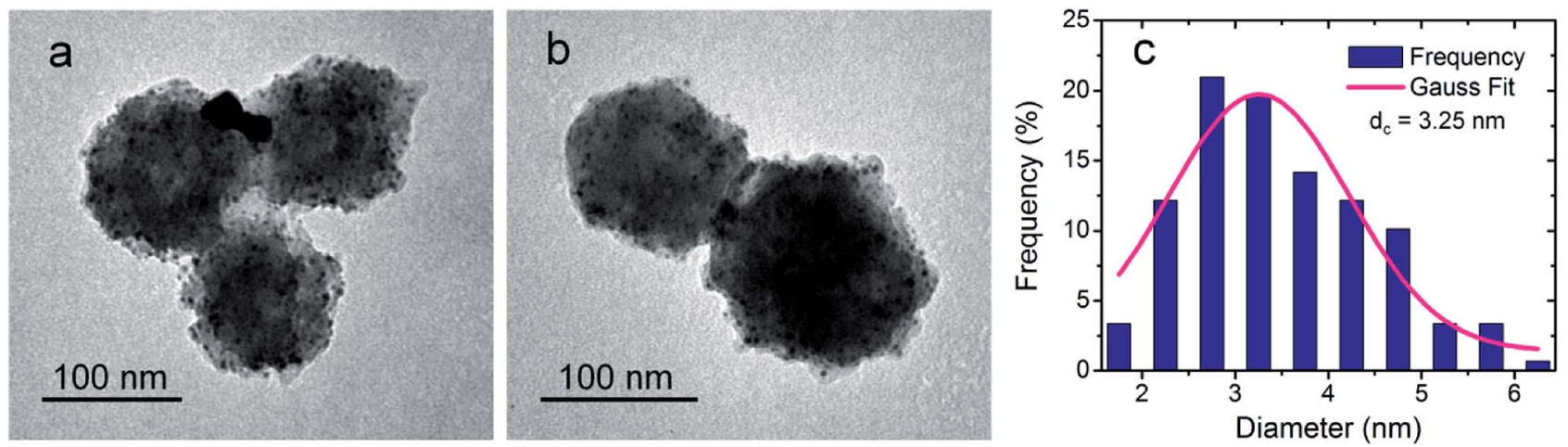

Fig. 4 ( $a$ and b) Bright field TEM images of the NSs obtained by the incubation of about 7 months at room temperature of an aqueous suspension: $\mathrm{HAuCl}_{4} 0.1 \mathrm{mM}, \mathrm{NaOH} 1 \mathrm{mM}$ and $4.43 \times 10^{12} \mathrm{SiO}_{2} \mathrm{MPs}$ per $\mathrm{L}$ ( $\mathrm{pH}=8.5$ ). (c) Size distribution of AuNPs supported/immersed in silica.

$$
\begin{aligned}
{\left[\mathrm{AuCl}_{4}\right]_{(\mathrm{aq})}^{-}+3 \mathrm{OH}^{-}{ }_{(\mathrm{aq})}+} & \mathrm{OMP}(\text { colloidal }) \\
& \mathrm{OMP} \mid \mathrm{Au}(\mathrm{OH})_{3(\text { colloidal })}+4 \mathrm{Cl}^{-}(\mathrm{aq})
\end{aligned}
$$

Since aqueous $\mathrm{Au}(\mathrm{OH})_{3}$ is unstable, the deposited $\mathrm{Au}(\mathrm{OH})_{3}$ is expected to decompose to form AuNPs:

$$
\begin{aligned}
& 4 \mathrm{OMP}\left|\mathrm{Au}(\mathrm{OH})_{3 \text { (colloidal) }} \rightarrow 4 \mathrm{OMP}\right| \mathrm{AuNPs} \text { (colloidal) }+3 \mathrm{O}_{2(\mathrm{~g})}+ \\
& 6 \mathrm{H}_{2} \mathrm{O}_{(1)}
\end{aligned}
$$

In this approach, an important factor is the control of the $\mathrm{Au}(\mathrm{OH})_{3}$ precipitation in order to favor heterogeneous nucleation onto the OMP over homogeneous nucleation minimizing the formation of free-standing AuNPs.

For the experiments, $\mathrm{SiO}_{2}$ MPs synthesized by Stöber method (mean size of $227 \mathrm{~nm}$, Section ESI-2 $\dagger$ ) were employed as substrate material. When the OPD method is carried on aqueous media, the reaction takes several months (see Section ESI-4 $\dagger$ ). Bright field TEM images of the OMP|AuNPs obtained are shown in Fig. 4.

The images show high contrast dots, which correspond to AuNPs, uniformly distributed onto the support material $\left(\mathrm{SiO}_{2}-\right.$ MPs). Comparing the images of these hybrid $\mathrm{NSs}\left(\mathrm{SiO}_{2}\right.$ MPs|AuNPs) with those of the substrate $\mathrm{SiO}_{2} \mathrm{MPs}$ (ESI-2 Fig. $\mathrm{S} 1 \mathrm{~b} \dagger$ ), it is evident that the incubation causes a change in the morphology of $\mathrm{SiO}_{2} \mathrm{MPs}$, which were initially smooth spheres. It is well known that dissolution of $\mathrm{SiO}_{2}$ can take place in alkaline solutions, ${ }^{55}$ this behavior can explain the deformation of the support material after the prolonged incubation time in alkaline conditions (7 months).

TEM images show that AuNPs are surrounded by support material as they are seen inside the silica matrix. Additionally, the size values of the AuNPs obtained from TEM images (Fig. 4) present a quasi-Gaussian distribution centered on $3 \mathrm{~nm}$, indicating that growth was not a predominant process. The fact that AuNPs do not grow larger, even after a prolonged reaction time (7 months), as well as the observation of the images, strongly suggests that AuNPs are immersed in the $\mathrm{SiO}_{2}$ matrix. Such a feature seems to be a consequence of an encapsulation effect caused by the chemical dissolution/re-precipitation of the silica by hydroxyl ions. Thus, these results show that it is possible to carry out the deposition of AuNPs over $\mathrm{SiO}_{2}$ MPs by OPD method in aqueous media. However, the necessary prolonged incubation times are themselves a disadvantage for practical synthetic purposes as well as they get worse the quality of the NSs by the loss of the $\mathrm{SiO}_{2} \mathrm{MPs}$ spherical morphology and by favoring the encapsulation of AuNPs with silica. A way to solve this issue is to employ acetone : water environments in order to accelerate the
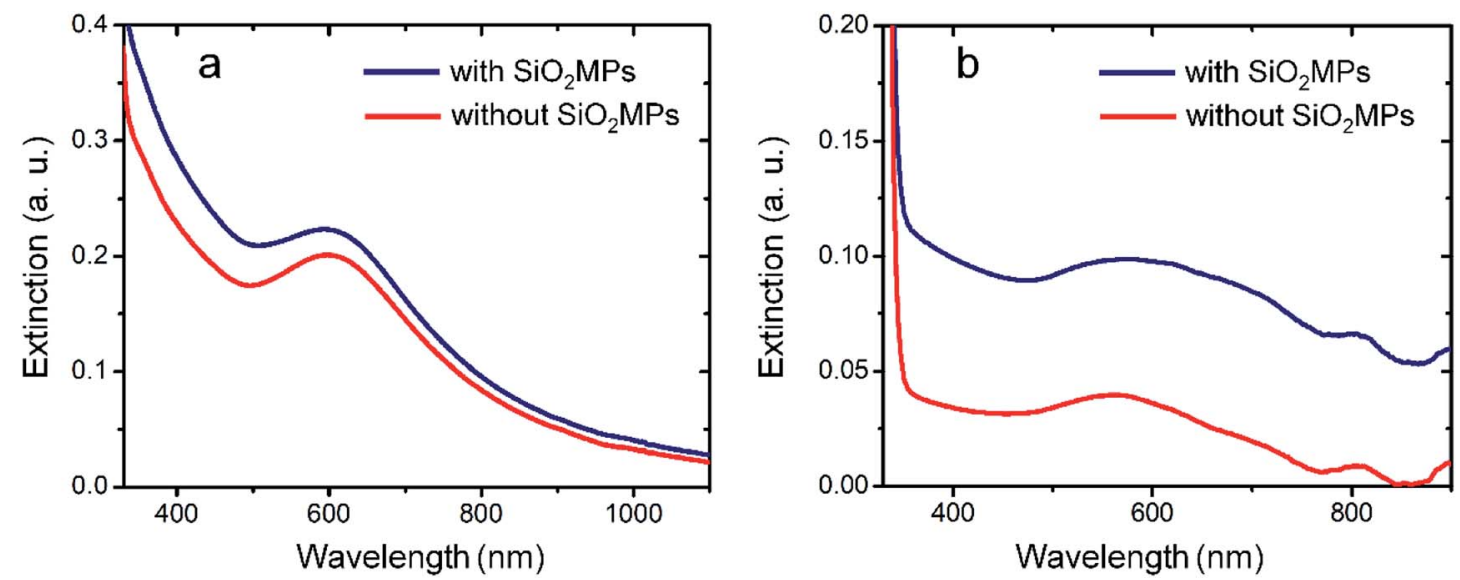

Fig. 5 UV-Visible spectra of reactive mixtures in acetone: water $90: 10$ with and without $\mathrm{SiO}_{2} \mathrm{MPs}$. (a) $\mathrm{HAuCl}_{4} 0.1 \mathrm{mM}$ and $\mathrm{NaOH} 5 \mathrm{mM}$ incubated at room temperature for 40 minutes. (b) $\mathrm{HAuCl}_{4} 0.1 \mathrm{mM}$ and $\mathrm{NaOH} 1 \mathrm{mM}$ gradually added incubated in an ice bath during 8.5 hours. 

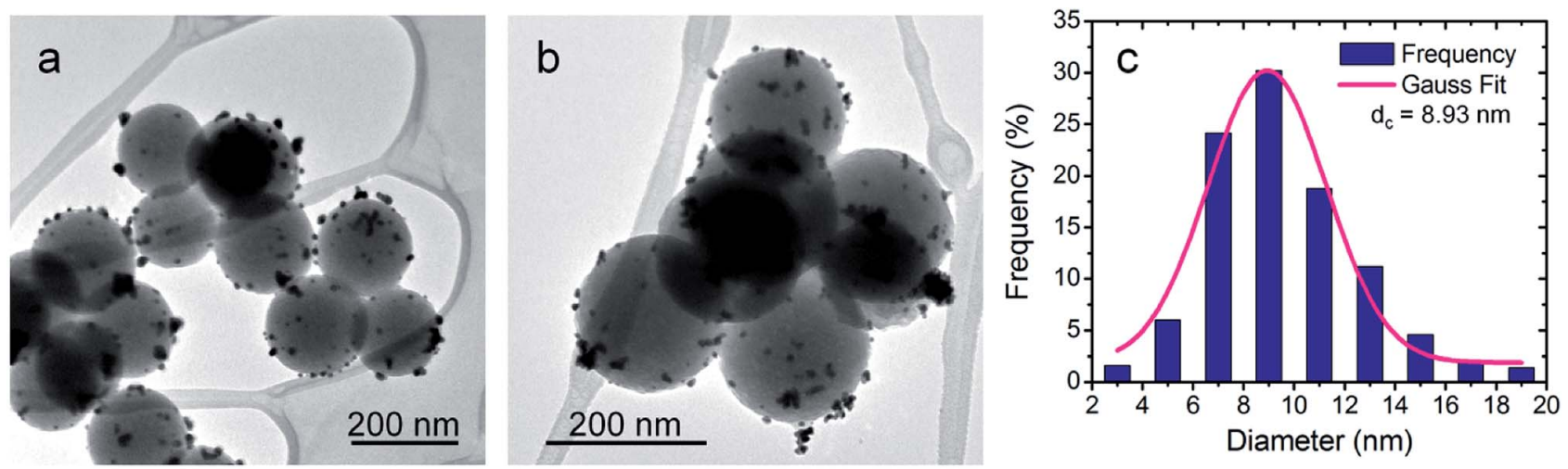

Fig. 6 ( $a$ and b) Bright field TEM images of the NSs obtained by the low-T protocol. (c) Size distribution of the supported AuNPs.

AuNPs production as discussed in the previous section (Fig. 2). The study of the effect of the variation of acetone : water ratio (see Section ESI-3 $\uparrow$ ) show that when the percentage of acetone is low, 10, 25 and even $50 \%, \mathrm{Au}(\mathrm{OH})_{3}$ precipitation/decomposition takes place quickly. Otherwise, in the case of $90 \%$ of acetone, $\mathrm{Au}(\mathrm{OH})_{3}$ precipitation/decomposition is delayed. Consequently, this behavior can be used to disfavor homogeneous over heterogeneous nucleation in order to achieve an effective decoration of substrate particles minimizing the formation of free-standing AuNPs. Therefore, two type of experiments were performed in parallel: the incubation of reactive mixtures in $90: 10$ acetone : water in presence of $\mathrm{SiO}_{2} \mathrm{MPs}$ and without them, this last type to be used as a control (Fig. 5a).

At room-temperature and in absence of $\mathrm{SiO}_{2} \mathrm{MPs}$, the spectrum profile exhibits a SPR peak associated to free-standing AuNPs after 40 minutes of reaction (red line). Interestingly,
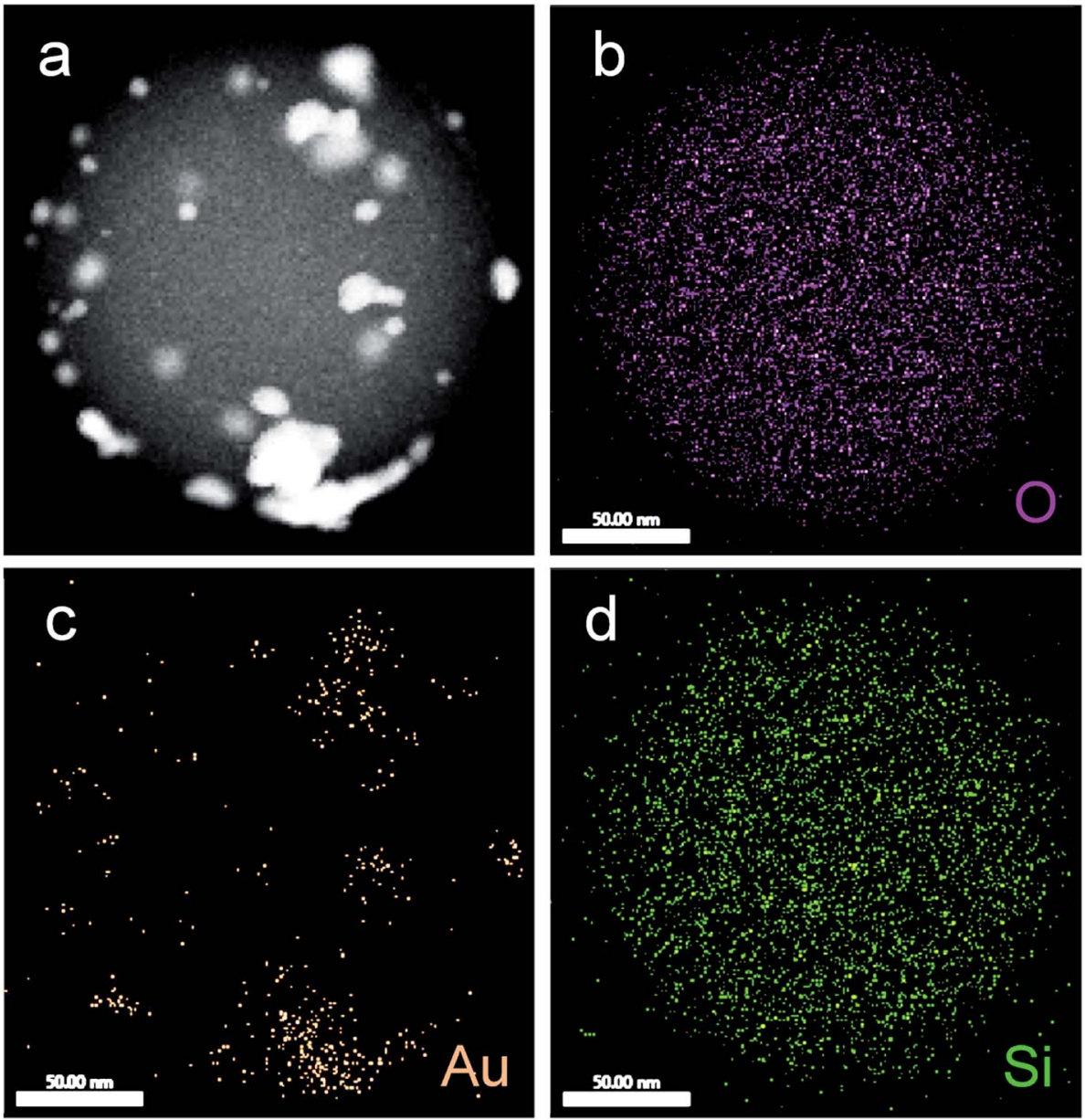

Fig. 7 A representative $\mathrm{SiO}_{2} \mathrm{MP} \mid$ AuNPs: (a) STEM image (dark field). EDS maps for: (b) K-oxygen, (c) L-gold and (d) K-silicon. 

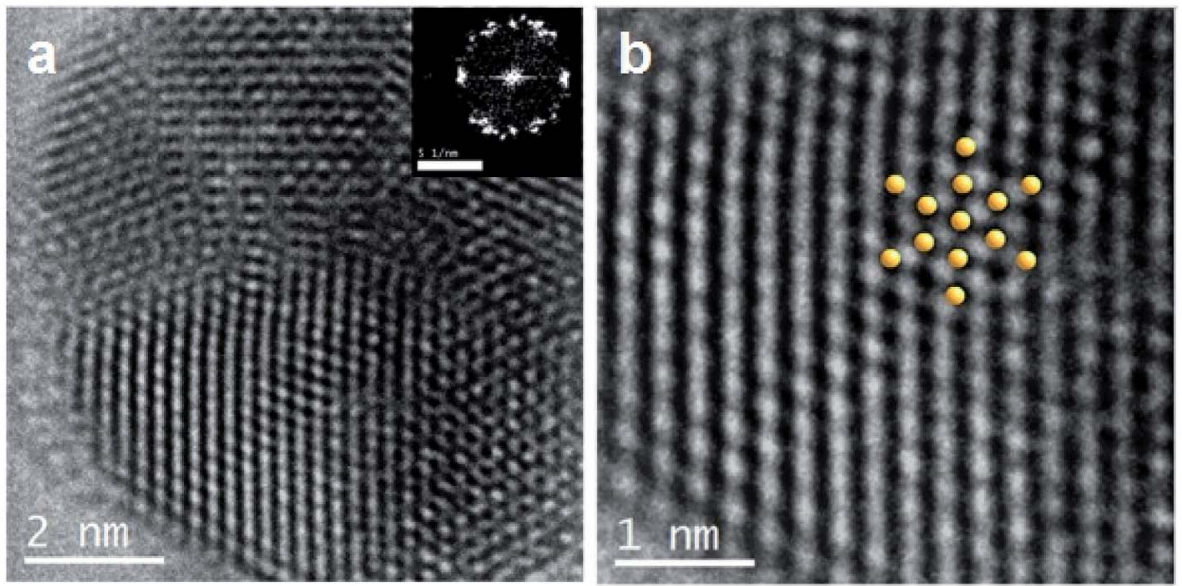

Fig. 8 (a) HRTEM bright field image of one AuNP over $\mathrm{SiO}_{2} \mathrm{MP}$; in set: FFT representation. (b) A magnified image of a; simulated structure of metallic gold superimposed.

this spectrum is in close resemblance with the one obtained in presence of $\mathrm{SiO}_{2}$ MPs (blue line). The likeness between both spectra indicates that the AuNPs are formed mainly in the bulk of the solution (free-standing) instead of onto the $\mathrm{SiO}_{2} \mathrm{MPs}$ surface. This is probably because the $\mathrm{Au}(\mathrm{OH})_{3}$ precipitation/ decomposition is too fast and uncontrolled under these conditions. Despite the fact that we managed to drastically reduce the incubation time for the formation of AuNPs, the use of acetone : water mixed environments is not enough by itself in favoring the heterogeneous over the homogeneous $\mathrm{Au}(\mathrm{OH})_{3}$ precipitation.
Hence, two main modifications were applied to the protocol: on the one hand, the final concentration of alkali was set at a lower value than those used previously, and it was achieved by the gradual additions of aliquots of strong base solution in order to have a more controlled $\mathrm{Au}(\mathrm{OH})_{3}$ precipitation; on the other hand, the incubation temperature was decreased near the freezing point of water to slow down the $\mathrm{Au}(\mathrm{OH})_{3}$ decomposition (low-T protocol). Under these conditions, there is more time for the $\mathrm{Au}(\mathrm{OH})_{3}$ precipitation/dissolution cycles to occur promoting its deposition on silica since it is thermodynamically favored over its homogeneous nucleation. We also performed a control experiment where the same protocol is carried on in
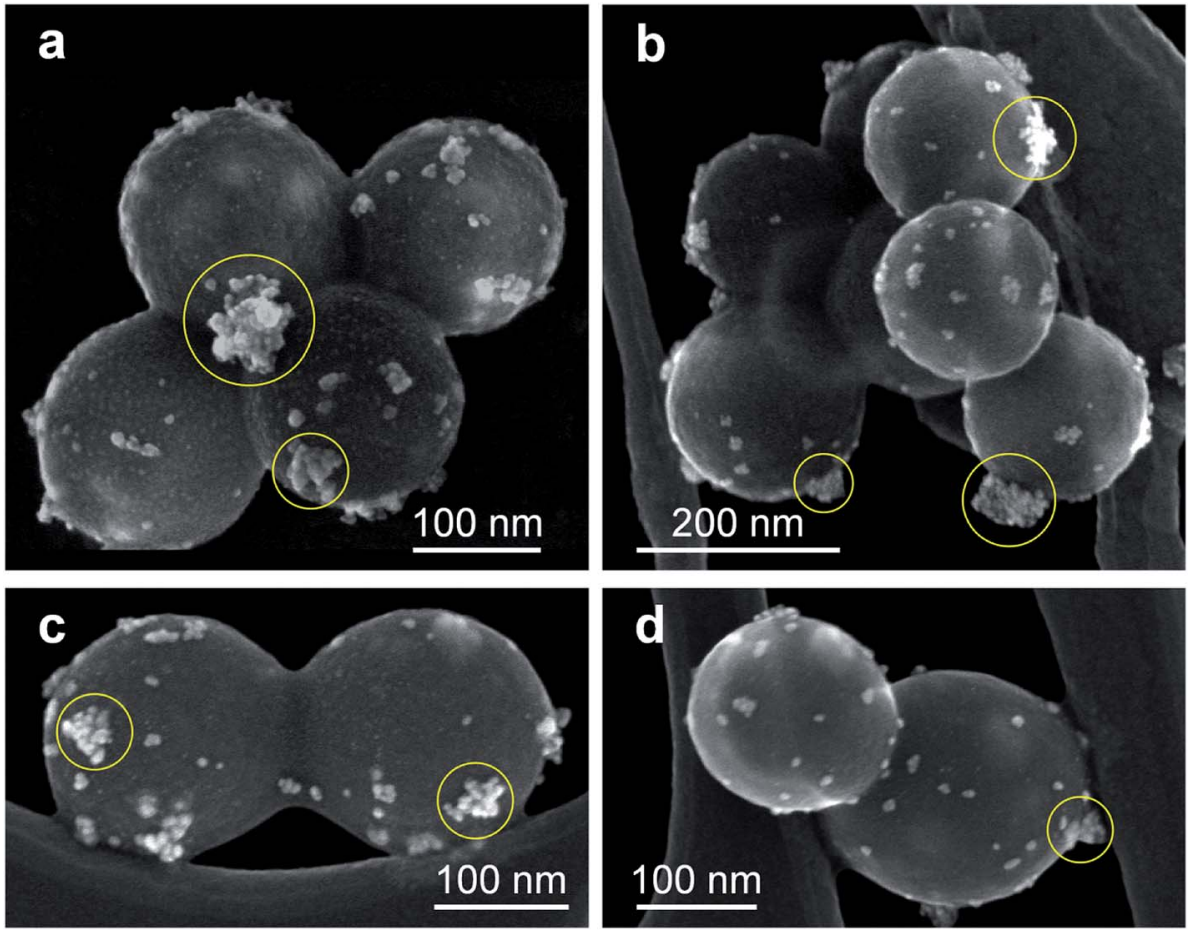

Fig. 9 Secondary electron images of the NSs obtained by the low-T protocol. 

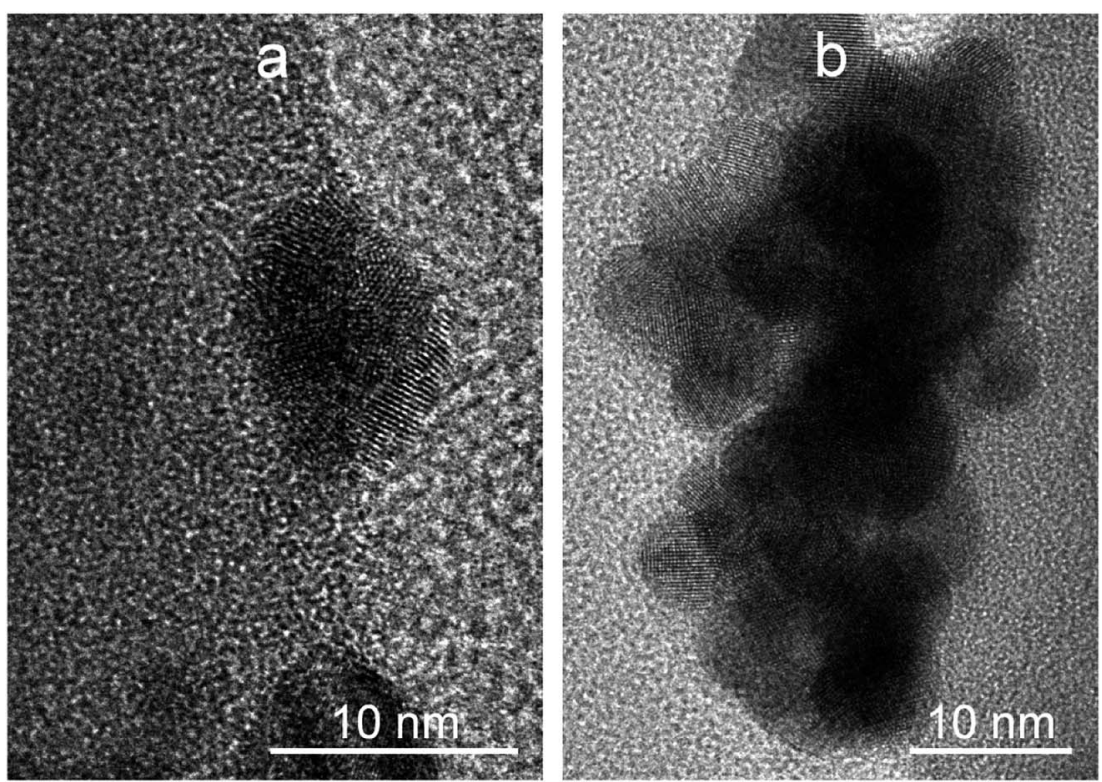

Fig. 10 AuNPs onto $\mathrm{SiO}_{2}$ NPs by HRTEM.

absence of the $\mathrm{SiO}_{2}$ MPs. As expected, by lowering the temperature the AuNPs take longer to be formed and the characteristic SPR extinction appears after several hours of reaction (Fig. 5b). Although AuNPs are formed in absence of $\mathrm{SiO}_{2} \mathrm{MPs}$ (red line), the extinction in presence of $\mathrm{SiO}_{2}$ MPs is notably higher (blue line), a feature pointing at different processes taking place under both conditions. These differences may indicate that silica have been decorated by AuNPs, if so, the set of experimental conditions consisting of lowering the incubation temperature, the alkali concentration and its gradual addition led to a more controlled $\mathrm{Au}(\mathrm{OH})_{3}$ precipitation where $\mathrm{Au}(\mathrm{OH})_{3}$ homogeneous precipitation is disfavored in comparison with the $\mathrm{Au}(\mathrm{OH})_{3}$ heterogeneous precipitation over the $\mathrm{SiO}_{2} \mathrm{MPs}$ surface. In order to confirm this interpretation samples were analyzed by electronic microscopy, results shown in the next section.

\section{Characterization of $\mathrm{SiO}_{2} \mathrm{MPs} \mid \mathrm{AuNPs}$ synthesized by low-T protocol}

The products obtained by using the optimized synthesis (low-T protocol) were characterized by TEM, STEM, HRTEM and EDS. The TEM images show NSs consisting of $\mathrm{SiO}_{2}$ MPs decorated with smaller globular particles of high contrast (Fig. 6 and ESI- 5 Fig. S4 $\dagger$ ). This fact is consistent with the presence of AuNPs over the substrate particles indicating an effective decoration process.

Fig. 7a shows a STEM image of an isolated NS characterized by EDS. The NS exhibits the characteristic $\mathrm{SiO}_{2} \mathrm{MP}$ spherical shape (dark grey pattern), as well as bright zones over the surface that would correspond to gold. The element distribution over the NS was mapped by tracing the X-ray signature of O, $\mathrm{Au}$ and Si (ESI-5 Fig. S5 $\dagger$ ). In contrast to the homogeneous spherical distribution of $\mathrm{O}$ and $\mathrm{Si}$ (Fig. $7 \mathrm{~b}$ and d, respectively), $\mathrm{Au}$ exhibits a heterogeneous pattern distribution for its EDS signature (Fig. 7c) that strongly resembles the bright pattern shown by the STEM image (Fig. 7a); a likeness that confirms the presence of gold over the surface of the $\mathrm{SiO}_{2} \mathrm{MPs}$. The metallic nature of the deposited gold was further confirmed by HRTEM. Fig. 8a shows the HRTEM image of a single gold nanoparticle deposited on a $\mathrm{SiO}_{2}$ particle. It is observed that the nanoparticle has a decahedron morphology with stable $\langle 111\rangle$ facets. ${ }^{56}$ The inset image in the upper right corner shows the Fast Fourier Transform (FFT), a representation of the crystalline structure in the reciprocal space. The FFT analysis gives a distance between the center point and the diffraction point ring of c.a. 4.021 $\mathrm{nm}^{-1}$, or an interplanar distance of $0.238 \mathrm{~nm}$, which correspond to the diffraction of the 111 planes in the FCC structure of metallic gold (JCPDS 04-0784). ${ }^{57}$ Also, in Fig. 8b are shown an amplified field of the image (a) and the simulated structure of metallic gold $\langle 111\rangle$ over-imposed, which perfectly fits the real atomic structure.

The quality of the $\mathrm{SiO}_{2} \mathrm{MPs}$ |AuNPs obtained can be appreciated from the TEM images in Fig. 6 and ESI-5 Fig. S4. $\dagger$ The images show that the AuNPs are homogeneously distributed onto the $\mathrm{SiO}_{2} \mathrm{MPs}$ surface and that the decoration degree is similar from one $\mathrm{SiO}_{2} \mathrm{MP}$ to another. Besides, it can be seen that the $\mathrm{SiO}_{2}$ MPs have not been dissolved keeping their spherical shape. Furthermore, free-standing AuNPs are not observed which indicates that the homogeneous nucleation of $\mathrm{Au}(\mathrm{OH})_{3}$ (followed by its decomposition) represents a minimal contribution under the synthesis conditions. An excellent size control of AuNPs is also achieved; the AuNPs have a mean size of $9 \mathrm{~nm}$ (Fig. 6c).

Similar conclusions are obtained from the secondary electron images shown in Fig. 9. The images show that the AuNPs (brighter zones) also form structures of higher size values with globular morphology (highlighted with yellow circles), probably as a consequence of a growth process. Besides, it is important to highlight that AuNPs are deposited onto the surface of the $\mathrm{SiO}_{2} \mathrm{MPs}$ instead of immersed inside the matrix. This is also observed in HRTEM images in which the crystalline structure of 
AuNPs (Fig. 10) and gold cumulus on the $\mathrm{SiO}_{2} \mathrm{MP}(\mathrm{c})$ are shown. These images also show that the surface of the AuNPs is exposed to the medium confirming the absence of encapsulation which represents a positive aspect for further applications.

\section{Summary and conclusions}

The experiments presented here show that aqueous/waterenriched colloidal $\mathrm{Au}(\mathrm{OH})_{3}$ decompose spontaneously for temperatures above the water freezing point to form AuNPs. Based on this reaction, we were capable of effectively produce high quality $\mathrm{SiO}_{2}$ MPs|AuNPs in a simple one-pot/one-step protocol without the need of previous functionalization of the substrate or calcination. The successful decoration achieved with the OPD method is in contrast with the poor decoration efficiency driven from soluble species (impregnation method), indicating that AuNPs formation is more advantageous from solid $\mathrm{Au}(\mathrm{OH})_{3}$ attached at the substrate surface than from a soluble precursor. In addition, the $\mathrm{SiO}_{2} \mathrm{MPs} \mid \mathrm{AuNPs}$ are produced with minimum by-product harvest (like free-standing AuNPs) and present a high degree of purity since the reaction remnants $\left(\mathrm{Na}^{+}, \mathrm{OH}^{-}\right)$and possible by-products $\left(\mathrm{O}_{2}\right)$ are of low polluting level and of easy elimination. The deposited AuNPs are small with a narrow size distribution and homogeneously distributed among the substrate. Moreover, in part because of the low temperature operation, the AuNPs produced are not encapsulated and, thus, present a free surface which is fundamental for most applications. This is an important advantage respect to the methods which require a calcination step since AuNPs encapsulation is a common issue at high temperatures. Finally, the method presented here can be easily extrapolated to be used for other support materials since the strategy of circumvent the gold poor wetting by $\mathrm{Au}(\mathrm{OH})_{3}$ precipitation is feasible of being applied to other non-metallic substrates (oxides and inorganic compounds).

\section{Conflicts of interest}

There are no conflicts to declare.

\section{Acknowledgements}

This research has been supported by means of different grants of CONICET (PIP 11220110100430), Program BID-FONCyT (PICT 2012-2286), SECYT of Universidad Nacional de Córdoba and the Welch Foundation grant AX-1615. M. A. Macchione thanks to Fulbright and Bunge \& Born institutions for supporting her stay in the Kleberg Advanced Microscopy Center at UTSA, Texas, USA.

\section{References}

1 A. Gharatape and R. Salehi, Recent Progress in Theranostic Applications of Hybrid Gold Nanoparticles, Eur. J. Med. Chem., 2017, 138, 221-233.

2 L. Dykman and N. Khlebtsov, Gold Nanoparticles in Biomedical Applications: Recent Advances and Perspectives to Biological and Medical, Chem. Soc. Rev., 2012, 41(6), 2256-2282.

3 E. C. Dreaden, A. M. Alkilany, X. Huang, C. J. Murphy and M. A. El-Sayed, The Golden Age: Gold Nanoparticles for Biomedicine, Chem. Soc. Rev., 2012, 41, 2740-2779.

4 K. Saha, S. S. Agasti, C. Kim, X. Li and V. M. Rotello, Gold Nanoparticles in Chemical and Biological Sensing, Chem. Rev., 2012, 112(5), 2739-2779.

5 R. Wilson, The Use of Gold Nanoparticles in Diagnostics and Detection, Chem. Soc. Rev., 2008, 37(9), 2028-2045.

6 J.-F. Li, C.-Y. Li and R. F. Aroca, Plasmon-Enhanced Fluorescence Spectroscopy, Chem. Soc. Rev., 2017, 46, 3962-3979.

7 A. Corma and H. Garcia, Supported Gold Nanoparticles as Catalysts for Organic Reactions, Chem. Soc. Rev., 2008, 37, 2096-2126.

8 Y. Zhang, X. Cui, F. Shi and Y. Deng, Nano-Gold Catalysis in Fine Chemical Synthesis, Chem. Rev., 2012, 112(4), 24672505.

9 A. S. Sharma, H. Kaur and D. Shah, Selective Oxidation of Alcohols by Supported Gold Nanoparticles: Recent Advances, RSC Adv. , 2016, 6, 28688-28727.

10 S. Liu, A. Qileng, J. Huang, Q. Gao and Y. Liu, Polydopamine as a Bridge to Decorate Monodisperse Gold Nanoparticles on $\mathrm{Fe}_{3} \mathrm{O}_{4}$ Nanoclusters for the Catalytic Reduction of 4Nitrophenol, RSC Adv., 2017, 7, 45545-45551.

11 G. A. Somorjai, A. M. Contreras, M. Montano and R. M. Rioux, Clusters, Surfaces, and Catalysis, PNAS, 2006, 103(28), 10577-10583.

12 M. Zahmakıran and S. Özkar, Metal Nanoparticles in Liquid Phase Catalysis; from Recent Advances to Future Goals, Nanoscale, 2011, 3, 3462-3481.

13 S. Liu, S.-Q. Bai, Y. Zheng, K. W. Shah and M.-Y. Han, Composite Metal-Oxide Nanocatalysts, ChemCatChem, 2012, 4, 1462-1484.

14 M. A. Brown, Y. Fujimori, F. Ringleb, X. Shao, F. Stavale, N. Nilius, M. Sterrer and H.-J. Freund, Oxidation of Au by Surface OH: Nucleation and Electronic Structure of Gold on Hydroxylated MgO (001), J. Am. Chem. Soc., 2011, 133(27), 10668-10676.

15 M. Valden, X. Lai and D. W. Goodman, Onset of Catalytic Activity of Gold Clusters on Titania with the Appearance of Nonmetallic Properties, Science, 1998, 281(5383), 1647-1650.

16 H. K. Jun, M. A. Careem and A. K. Arof, Plasmonic Effects of Quantum Size Gold Nanoparticles on Dye-Sensitized Solar Cell., Mater Today., 2016, 3(S1), S73-S79.

17 S. Mukherjee, P. S. Das, M. Choudhuri, A. Datta, J. Ghosh, B. Saha, K. Koshmak, S. Nannarone and A. K. Mukhopadhyay, Tuning the Band Gap in Titanium Dioxide Thin Films by Surfactant Mediated Confinement and Patterning of Gold Nanoparticles, J. Phys. Chem. C, 2017, 121(39), 21311-21323.

18 H. Shi, S. Zhang, X. Zhu, Y. Liu, T. Wang, T. Jiang, G. Zhang and H. Duan, Uniform Gold Nanoparticles Decorated $\{001\}$ Faceted Anatase TiO2 Nanosheets for Enhanced Solar Light Photocatalytic Reactions, ACS Appl. Mater. Interfaces, 2017, 9(42), 36907-36916. 
19 P. She, K. Xu, S. Zeng, Q. He, H. Sun and Z. Liu, Investigating the Size Effect of $\mathrm{Au}$ Nanospheres on the Photocatalytic Activity of Au-Modified ZnO Nanorods, J. Colloid Interface Sci., 2017, 1(499), 76-82.

20 T. C. Damato, C. C. S. De Oliveira, R. A. Ando and P. H. C. Camargo, A Facile Approach to $\mathrm{TiO}_{2}$ Colloidal Spheres Decorated with Au Nanoparticles Displaying WellDefined Sizes and Uniform Dispersion, Langmuir, 2013, 29(5), 1642-1649.

21 P. Strobbia, A. J. Henegar, T. Gougousi and B. M. Cullum, Layered Gold and Titanium Dioxide Substrates for Improved Surface Enhanced Raman Spectroscopic Sensing, Appl. Spectrosc., 2016, 70(8), 1375-1383.

22 F. Bao, J.-L. Yao and R.-A. Gu, Synthesis of Magnetic $\mathrm{Fe}_{2} \mathrm{O}_{3} /$ Au Core/Shell Nanoparticles for Bioseparation and Immunoassay Based on Surface-Enhanced Raman Spectroscopy, Langmuir, 2009, 25(18), 10782-10787.

23 Y. S. Chi, H. P. Lin and C. Y. Mou, CO Oxidation over Gold Nanocatalyst Confined in Mesoporous Silica, Appl. Catal., A, 2005, 284(1-2), 199-206.

$24 \mathrm{Q}$. Fu and T. Wagner, Interaction of Nanostructured Metal Overlayers with Oxide Surfaces, Surf. Sci. Rep., 2007, 62, 431-498.

25 J. M. Campelo, D. Luna, R. Luque, J. M. Marinas and A. A. Romero, Sustainable Preparation of Supported Metal Nanoparticles and Their Applications in Catalysis, ChemSusChem, 2009, 2, 18-45.

26 L. Prati and A. Villa, The Art of Manufacturing Gold Catalysts, Catalysts, 2012, 2(1), 24-37.

27 Synthesis of Solid Catalysts, ed. K. P. de Jong, WILEY-VCH Verlag GmbH \& Co. KGaA, Weinheim, 2009, ISBN: 978-3527-32040-0.

28 V. G. Pol, D. N. Srivastava, O. Palchik, V. Palchik, M. A. Slifkin, A. M. Weiss and A. Gedanken, Sonochemical Deposition of Silver Nanoparticles on Silica Spheres, Langmuir, 2002, 18(8), 3352-3357.

29 A. L. I. Saad, C. Vard, M. Abderrabba and M. M. Chehimi, Triazole/Triazine-Functionalized Mesoporous Silica as a Hybrid Material Support for Palladium Nanocatalyst, Langmuir, 2017, 33(28), 7137-7146.

30 J. K. Papp, J. D. Forster, C. M. Burke, H. W. Kim, A. C. Luntz, R. M. Shelby, J. Urban and B. D. Mccloskey, Poly(vinylidene Fluoride) (PVDF) Binder Degradation in $\mathrm{Li}-\mathrm{O}_{2}$ Batteries: A Consideration for the Characterization of Lithium Superoxide, J. Phys. Chem. Lett., 2017, 8(6), 1169-1174.

31 P. Xu, X. Liang, N. Chen, J. Tang, W. Shao, Q. Gao and Z. Teng, Magnetic Separable Chitosan Microcapsules Decorated with Silver Nanoparticles for Catalytic Reduction of 4-Nitrophenol, J. Colloid Interface Sci., 2017, 507, 353-359.

32 D. K. Lee, Y. Song, V. T. Tran, J. Kim, E. Y. Park and J. Lee, Preparation of Concave Magnetoplasmonic Core-Shell Supraparticles of Gold-Coated Iron Oxide via Ion-Reducible Layer-by-Layer Method for Surface Enhanced Raman Scattering, J. Colloid Interface Sci., 2017, 499, 54-61.

33 E. Redolfi Riva, I. Pastoriza-santos, A. Lak, T. Pellegrino, J. Pérez-juste and V. Mattoli, Plasmonic/magnetic Nanocomposites: Gold Nanorods-Functionalized Silica
Coated Magnetic Nanoparticles, J. Colloid Interface Sci., 2017, 15(502), 201-209.

34 B. Ballarin, D. Barreca, E. Boanini, E. Bonansegna, M. C. Cassani, G. Carraro, S. Fazzini, A. Mignani, D. Nanni and D. Pinelli, Functionalization of Silica through ThiolYne Radical Chemistry: A Catalytic System Based on Gold Nanoparticles Supported on Amino-Sulfide-Branched Silica, RSC Adv., 2016, 6, 25780-25788.

35 N. Phonthammachai and T. J. White, One-Step Synthesis of Highly Dispersed Gold Nanocrystals on Silica Spheres, Langmuir, 2007, 23(23), 11421-11424.

36 K. Masatake Haruta and I. Tetsuhiko Kobayashi, Method for the Production of Ultra-Fine Gold Particles Demobilized on a Metal Oxide, US Pat., Patent number 4839327, 1989.

37 M. Haruta, Gold as a Novel Catalyst in the 21st Century: Preparation, Working Mechanism and Applications, Gold Bull., 2004, 37(1-2), 27-36.

38 W.-S. Lee, R. Zhang, M. C. Akatay, C. D. Baertsch, E. A. Stach, F. H. Ribeiro and W. N. Delgass, Differences in Catalytic Sites for CO Oxidation and Propylene Epoxidation on $\mathrm{Au}$ Nanoparticles, ACS Catal., 2011, 1(10), 1327-1330.

39 S. Ramesh, Y.-J. Lee, S. Msolli, J.-G. Kim, H. S. Kim and J.-H. Kim, Synthesis of a $\mathrm{Co}_{3} \mathrm{O}_{4} @ g o l d / M W C N T /$ polypyrrole Hybrid Composite for DMMP Detection in Chemical Sensors, RSC Adv., 2017, 7, 50912-50919.

40 M. Bowker, J. J. Crouch, A. F. Carley, P. R. Davies, D. J. Morgan, G. Lalev, S. Dimov and D. T. Pham, Encapsulation of $\mathrm{Au}$ Nanoparticles on a Silicon Wafer during Thermal Oxidation, J. Phys. Chem. C, 2013, 117(41), 21577-21582.

41 Q. Zhang, I. Lee, J. B. Joo, F. Zaera and Y. Yin, Core-Shell Nanostructured Catalysts, Acc. Chem. Res., 2013, 46(8), 1816-1824.

42 I. Yoshiro, K. Shiori, A. Ryota, M.-I. Clara and K. Takeshi, Highly Stable Silica-Coated Gold Nanoflowers Supported on Alumina, Langmuir, 2017, 33(17), 4313-4318.

43 K. Qian, J. Fang, W. Huang, B. He, Z. Jiang, Y. Ma and S. Wei, Chemical Understanding the Deposition - Precipitation Process for the Preparation of Supported Au Catalysts, $J$. Mol. Catal. A, 2010, 320, 97-105.

44 M. A. Macchione, O. A. Douglas-Gallardo, L. A. Pérez, N. Passarelli, R. Moiraghi, A. Spitale, D. Bahena, F. Y. Oliva, M. M. Mariscal, M. José-Yacamán, et al., OneStep/one-Pot Decoration of Oxide Microparticles with Silver Nanoparticles, J. Colloid Interface Sci., 2014, 428, 32-35.

45 O. A. Douglas-Gallardo, R. Moiraghi, M. A. Macchione, J. A. Godoy, M. A. Pérez, E. A. Coronado and V. A. Macagno, Silver Oxide Particles/silver Nanoparticles Interconversion: Susceptibility of Forward/backward Reactions to the Chemical Environment at Room Temperature, RSC Adv., 2012, 2, 2923-2929.

46 A. A. Semenova, E. A. Goodilin and Y. D. Tretyakov, Direct Preparation of Anion-Free Pure Silver Hydrosols, Mendeleev Commun., 2011, 21(6), 312-314.

47 W. Stöber, A. Fink and E. Bohn, Controlled Growth of Monodisperse Silica Spheres in the Micron Size Range, $J$. Colloid Interface Sci., 1968, 26(1), 62-69. 
48 G. H. Bogush, M. A. Tracy and C. F. Zukoski, Preparation of Monodisperse Silica Particles: Control of Size and Mass Fraction, J. Non-Cryst. Solids, 1988, 104(1), 95-106.

49 J. J. Razink and N. E. Schlotter, Correction to "Preparation of Monodisperse Silica Particles: Control of Size and Mass Fraction" by G. H. Bogush, M. A. Tracy and C. F. Zukoski IV, J. Non-Cryst. Solids, 1988, 104, 95-106, J. Non-Cryst. Solids, 2007, 353(30-31), 2932-2933.

50 A. Van Blaaderen and A. Vrij, Synthesis and Characterization of Monodisperse Colloidal Organo-Silica Spheres, J. Colloid Interface Sci., 1993, 156(1), 1-18.

$51 \mathrm{H}$. H. Morris, Study of the Chemistry of Gold at High Temperatures and Pressures, J. Am. Chem. Soc., 1918, 40(6), 917-927.

52 M. J. Nicol, C. a. Fleming and R. L. Paul, The Chemistry of the Extraction of Gold, in The Extractive Metallurgy of Gold in South Africa, ed. G. G. Stanley, South African Institute of Mining and Metallurgy, 1987, pp 831-905.
53 I. V. Mironov and L. D. Tsvelodub, Gold(III) Chlorohydroxo Complexes in Alkaline Aqueous Solutions, Russ. J. Inorg. Chem., 2000, 45(4), 633-637.

54 I. V. Mironov, Properties of Gold (III) Hydroxide and Aquahydroxogold (III) Complexes in Aqueous Solution Properties of Gold (III) Hydroxide and Aquahydroxogold (III) Complexes in Aqueous Solution, Russ. J. Inorg. Chem., 2005, 50(7), 1115-1120.

55 Y. Niibori, M. Kunita, O. Tochiyama and T. Chida, Dissolution Rates of Amorphous Silica in Highly Alkaline Solution, J. Nucl. Sci. Technol., 2000, 37(4), 349-357.

56 M. J. Yacamán, J. a. Ascencio, H. B. Liu and J. GardeaTorresdey, Structure Shape and Stability of Nanometric Sized Particles, J. Vac. Sci. Technol. B, 2001, 19(4), 1091-1103.

57 A. Mikalauskaite, R. Kondrotas, G. Niaura and A. Jagminas, Gold-Coated Cobalt Ferrite Nanoparticles via MethionineInduced Reduction, J. Phys. Chem. C, 2015, 119(30), 1739817407. 